\title{
Polyamines: The possible missing link between mental disorders and epilepsy (Review)
}

\author{
GIULIA BAROLI ${ }^{1}$, JONATHAN REINOSO SANCHEZ ${ }^{1}$, ENZO AGOSTINELLI ${ }^{2,3}$, \\ PAOLO MARIOTTINI $^{1,3}$ and MANUELA CERVELLI ${ }^{1,3}$ \\ ${ }^{1}$ Department of Science, University of Rome 'Roma Tre', I-00146 Rome; \\ ${ }^{2}$ Department of Biochemical Sciences 'Rossi Fanelli', University of Rome 'La Sapienza', \\ I-00185 Rome; ${ }^{3}$ International Polyamines Foundation-ONLUS, I-00159 Rome, Italy
}

Received February 8, 2019; Accepted July 22, 2019

DOI: $10.3892 /$ ijmm.2019.4401

\begin{abstract}
Polyamines are small positively charged alkylamines that are essential in a number of crucial eukaryotic processes, like normal cell growth and development. In normal physiological conditions, intracellular polyamine content is tightly regulated through a fine regulated network of biosynthetic and catabolic enzymes and a transport system. The dysregulation of this network is frequently associated to different tumors, where high levels of polyamines has been detected. Polyamines also modulate ion channels and ionotropic glutamate receptors and altered levels of polyamines have been observed in different brain diseases, including mental disorders and epilepsy. The goal of this article is to review the role of polyamines in mental disorders and epilepsy within a frame of the possible link between these two brain pathologies. The high comorbidity between these two neurological illnesses is strongly suggestive that they share a common background in the central nervous system. This review proposes an additional association between the noradrenalin/serotonin and glutamatergic neuronal circuits with polyamines. Polyamines can be considered supplementary defensive shielding molecules, important to protect the brain from the development of epilepsy and mental illnesses that are caused by different types of neurons. In this contest, the modulation of polyamine metabolism may be a novel important target for the prevention and therapeutic treatment of these diseases that have a high impact on the costs of public health and considerably affect quality of life.
\end{abstract}

Correspondence to: Dr Manuela Cervelli, Department of Science, University of Rome 'Roma Tre', Viale Guglielmo Marconi 446, I-00146 Rome, Italy

E-mail: manuela.cervelli@uniroma3.it

Key words: polyamines, mental disorders, monoaminergic system, anxiety, epilepsy, comorbidity

\section{Contents}

1. Polyamine metabolism

2. Polyamines and modulation of ion channels

3. Polyamines and mental disorders

4. Polyamines and epilepsy

5. Mood disorders and epilepsy

6. Conclusion

\section{Polyamine metabolism}

Cellular polyamines. Polyamines (PAs) are ubiquitous, short, positively charged aliphatic amines essential for normal cell growth, proliferation and differentiation. Although PAs occur in prokaryotic and eukaryotic cells, from plants and animals $(1,2)$, the typical PAs synthesized by mammals are spermidine (Spd), and spermine (Spm), from the diamine putrescine (Put), (3). Some studies have demonstrated an alternative pathway of PA synthesis, where agmatine (Agm) can slightly contribute as a potential source of Put (4-6). Agmatine, Put, Spd, Spm and the acetylated derivatives N1-acetylspermidine (AcSpd) and N1-acetylspermine (AcSpm; Fig. 1) have fundamental roles in cellular homeostasis and their optimal cellular content is maintained via complex regulatory mechanisms (7). Among the various functional roles of the natural PAs, the regulation of gene transcription and post-transcriptional modifications, as well as the modulation of synaptic activity are noticeable. For this reason, these molecules are continually under active investigation in wide-ranging research areas, from neuroscience, cancer, cell differentiation and development (8-10).

Polyamine interconvertion pathway. Two step-limiting enzymes tightly regulate PA biosynthesis: ornithine decarboxylase (ODC), which produces Put by decarboxylation of ornithine and S-adenosylmethionine decarboxylase, which synthesizes S-adenosyl-methioninamine from S-adenosyl-L-methionine. Two specific aminopropyl transferases, Spd synthase and Spm synthase are also involved in the biosynthesis of PAs, adding the aminopropyl group to Put and Spd, respectively (11-13). Conversely, PA catabolism is finely regulated by the three enzymes: Spd and Spm N1-acetyltransferase 
(SSAT), N1-acetylpolyamine oxidase (PAOX) and spermine oxidase (SMOX) (Fig. 2). The enzyme SSAT transfers acetyl groups from acetyl-coenzyme A to the N1 position of both Spd and Spm to produce AcSpd and AcSpm, respectively. These substrates are oxidized by the flavoprotein PAOX to produce Spd and Put, respectively, and 3-aceto-aminopropanal (3-AP) and hydrogen peroxide $\left(\mathrm{H}_{2} \mathrm{O}_{2}\right)(14,15)$. Another enzyme involved in the PA catabolism is SMOX that specifically oxidases Spm producing Spd, 3-aminopropanal and $\mathrm{H}_{2} \mathrm{O}_{2}(15,16)$. Polyamines can be biosynthesized and imported into cells by ubiquitous PA transporters (PTSs). As a result of the multiple enzymes involved in the PA metabolism and taking also into account the cellular uptake and export of PAs, the individual content of each PA is constantly well buffered within the mammalian cells. The typical PTS is saturable, strongly energy dependent and has a high affinity for its substrates (generally ranging from $10^{-7}$ to $10^{-5} \mathrm{M}$, depending on the PA species and cell type) (17). Polyamines content can be regulated by internalization through plasma membrane PA permeases $(17,18)$. Notwithstanding the strong cellular PA homeostasis, this metabolism can be altered by physiological stimuli, as well as in many pathological conditions like cancer, inflammation, neurodegeneration and others (9). Mammalian cell PA metabolism is summarized in Fig. 2.

\section{Polyamines and modulation of ion channels}

Polyamines and the brain. The concentration of PAs varies greatly in different tissues. In vertebrates, the brain behaves as an autonomous and closed system with regard to the PA metabolism. There is a high variation in PA levels between the different brain regions and in general, the levels of Spd and Spm are much higher than those of Put (19). Different studies have shown a neuroprotective role of PAs, nevertheless in pathological conditions they can cause neurotoxicity due to their oxidation and conversion into aldehydes and reactive oxygen species (20-23). In recent years, the key role of PAs in different brain syndromes and diseases has been increasingly recognized. This role seems to be mainly due to their ability to modulate and regulate different ion channels (24).

Ion channel modulation by polyamines. Endogenous PAs, in particular Spm, are able to interact and modulate different ion channels and receptors involved in the maintenance of homeostasis of calcium, sodium and potassium. Intracellular Spm, at $\mu \mathrm{M}$ concentrations, acts as an important blocker of inwardly rectifying potassium channels, by specifically plugging the ion channel pore. In fact, an increase of its content is responsible for an increase of the channel gating and rectification, which leads to a rise in cellular excitability (25). Polyamines can also modulate the activities of ion channels responsible for the flux of cations through the cellular membrane. Additionally, PAs, by different intra/extra cellular interaction sites, can modulate voltage activated calcium channels. A specific interaction exists between PAs and the a1 subunit of L-type calcium channel. Only Put induces an increase in the flux of current via the protein kinase C pathway, while Spd and Spd are unable to produce this effect (26). These channels are involved in synaptic transmission and plasticity and respond to ligands such as glutamate. Ionotropic glutamate receptors are divided into three groups: N-methyl-D-aspartate receptor (NMDAR); $\alpha$-amino-3- hydroxy-5-methyl-4-isoxazolepropionic acid receptor (AMPAR) and kainate receptor (KAR). Intracellular PAs can block the pore of the AMPAR and KAR, altering sodium and calcium flux, causing channels rectification, in particular affecting AMPAR lacking a GluR2 subunit and KAR lacking a GluR6 subunit (27). The AMPAR rectification by Spm is dependent on the voltage and can regulate the calcium flux and the excitability threshold of synapses (28). Polyamines can regulate another glutamate receptor, the NMDAR, a channel gate calcium and sodium containing two copies of NR1 and NR2 subunits. Polyamines, Spm in particular, are able either to stimulate or inhibit the NMDAR, according to the concentrations of glutamate, glycine and magnesium. Spermine can increase the frequency of the channel opening causing a strengthening of the NMDAR current in presence of saturating concentration of glycine. Only in the absence of magnesium extracellular Spm can block NMDAR in a voltage dependent manner. The inhibitory effect may take place because the extracellular Spm interacts with the negatively charged residues of the NMDAR, creating a steric obstruction for the passage of ions leading to a reduction of current through the channel. At physiological magnesium concentrations, only Spm-driven NMDAR stimulation can occur (29).

\section{Polyamines and mental disorders}

Polyamines and neurological disorders. According to the World Health Organization one in four people will be affected by mental or neurological disorders at some point in their lives; in the USA nearly $50 \%$ of the adult population have experienced depression or anxiety disorder, which are the most common and debilitating forms of mental illnesses associated with a substantially decreased of quality life (30). Currently $\sim 450$ million people suffer from such conditions, for this reason mental illnesses are a type of worldwide disabilities (31). In fact, this type of disability is widely recognized as a major illness responsible for indirect costs because of its high economic impact on society (32). According to the Bureau of Economic Analysis's Health Care Satellite Account, in 2013 in the USA $\sim \$ 89$ billion has been spent on the treatment of mental illnesses (33). In the past years, many studies have focused on understanding the mechanisms underlying mental illness (34-39); much of the literature has analyzed the role of the monoaminergic system, in particular, the serotonin and catecholamine involvement in the etiology of these pathologies (40-42). The impairment of the monoaminergic system alone cannot explain all the aspects related to these diseases, since over the years it has become increasingly clear the contribution of other players such as PAs (43). One of the early hints of the neurobiological role of PAs was the serendipitous discovery that antimalarial drugs, with psychosis side effects, contained a Spd moiety in their structure (44). As described above, PAs can affect neuronal excitability since they interact with different transmembrane channels (27), in the light of this important role in central nervous system (CNS), over the last three decades extensive research has pointed out their implications in different psychiatric conditions. In fact, an alteration of the PA content and their metabolic enzymes have been 
<smiles>NCCCCN</smiles>

putrescine<smiles>NCCCCNC(N)N</smiles>

agmatine<smiles>NCCCCNCCCN</smiles>

spermidine<smiles>NCCCNCCCCNCCCN</smiles>

spermine<smiles>CC(=O)NCCCNCCCCN</smiles>

$\mathrm{N}^{1}$-acetylspermine<smiles>CC(=O)NCCCNCCCCNCCCN</smiles>

$\mathrm{N}^{1}$-acetylspermine

Figure 1. Chemical structures of mammalian polyamines.

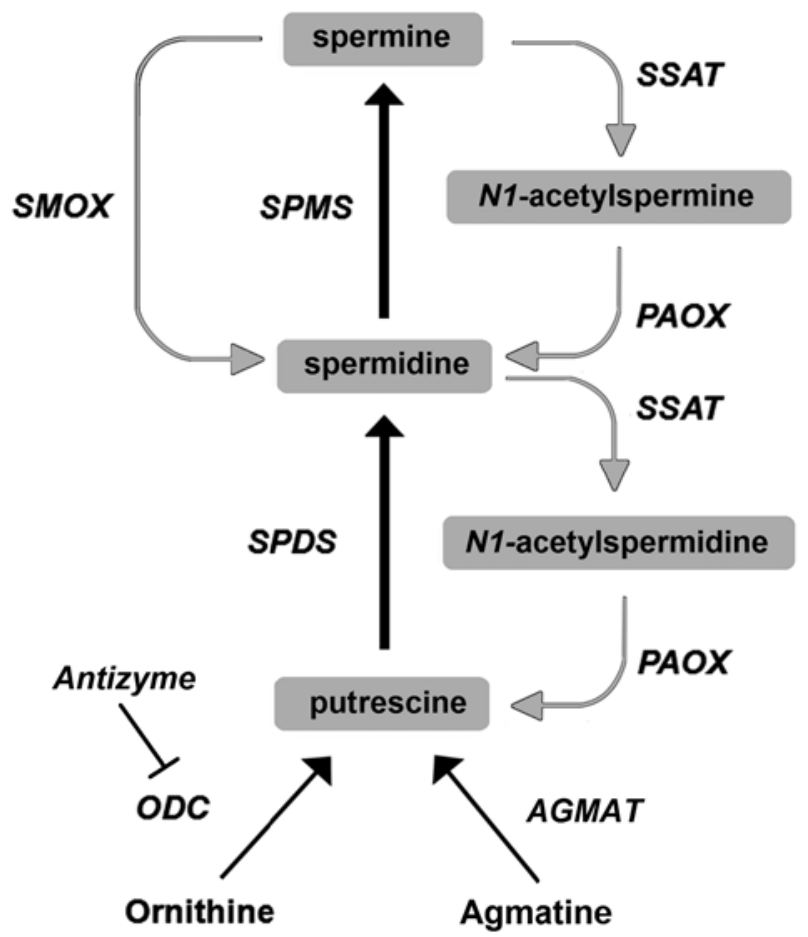

Figure 2. Mammalian PA metabolism. Schematic representation of PA metabolism showing enzyme network and substrate interconversion pathways. Anabolic and catabolic pathways are indicated by black and grey arrows, respectively. AGMT, agmatinase; ODC, ornithine decarboxylase; PAOX, $N^{1}$-acetylpolyamine oxidase; SAMDC, S-adenosyl-methionine decarboxylase; SMOX, spermine oxidase; SPMS, spermine synthase; SPDS, spermidine synthase; SSAT, Spd and Spm $N^{1}$-acetyltransferase; PA, polyamine.

found in different mental illness, such as schizophrenia, mood and anxiety disorders (45).

Polyamines and schizophrenia. Schizophrenia animal models and human patients have shown dysregulation of the PA metabolism (46). In patients, the blood's PA content alteration seems to be due to the pharmacological treatment response to neuroleptics drugs since these changes have not been observed in untreated patients and in neuroleptic-resistant schizophrenia patients (45). Early studies have pointed out the involvement of PAOX in schizophrenia, where an increased level of this enzyme has been found in schizophrenic patient serums (47-49). The contribution of ODC is still poorly understood, since no differences regarding its levels were found in patients while an increase of ODC activity was observed in cortical neurons from a rat model of schizophrenia (50). Nonetheless, several works confirm the importance of ornithine metabolism in the genesis of schizophrenic disease because ornithine aminotransferase, antizyme inhibitor and ornithine cyclodeaminase were found to be decreased in the prefrontal cortex of patients (51-53). One of the hypothesises proposed to validate the role of brain PAs in the aetiology of schizophrenia was that they can modulate dopamine pathway; the latter shares with the higher PA Spd and Spm, the S-adenosyl-methioninamine common precursor in the biosynthetic pathway. Furthermore, NMDAR modulation by Spd and Spm, as described above, could explain the hypofunctional NMDAR signalling in schizophrenia.

Polyamines and depression. Alteration in PA systems have also been found in animal models of depression. In rats affected by depression a hippocampal decrease of Put, Spd and Spm has been observed, while only a decrease of Put levels was observed in the nucleus accumbens (54). Putrescine was shown to possess antidepressant properties, since its administration by injection can reduce immobility time in forced swimming and tail suspension tests. Analysis of plasma from humans suffering from depression showed a high level of Agm that is restored to normal levels after antidepressant treatments, highlighting the critical role of this molecule in depression (45). Previously, the role of neurotransmitter has been proposed for Agm in the CNS. This was confirmed by its accumulation in synaptic vesicles and by the ability of Agm to be secreted following depolarization (55). Moreover, it has been proved that Agm is a selective antagonist of the NMDA polyamine-binding site (56). All these data confirm the involvement of the PA system in depression. In a similar way to what was observed in schizophrenic patients, high levels of PAs were also found in the plasma of patients suffering from depression (49). Evidence showed that the transcript and protein levels of different elements of the PA system are altered in several brain regions of suicide completers; in particular post-mortem studies have highlighted changes in the SSAT enzyme which shows a lower level of expression compared with healthy people $(43,57)$. It has been proposed that in the brains of depressed people, the lowering of the expression of SSAT could be a compensatory mechanism to cope with the excessive presence of PA (57). 
Polyamines and stress response. Over the past decade, great attention has been focused on the role of PAs in the context of stress response and particularly on its causal relationship with the morbidity of anxiety and psychiatric disorders. This pathological condition is called PAs stress response (PSR), it can be triggered by different types of stressors and this response can be modulated in accordance with the stressor intensity (58). In the CNS acute stressors do not increase the concentrations of all PAs but rather they lead to an accumulation of Put and Agm as well as an increase of ODC activity. Contrary to the events that have been observed in the CNS, in which the PSR can be activated independently, in the peripheral nervous system PSR trigger occurs only after the activation of the hypothalamic-pituitary axis. Following acute stress, changes are only appreciated in Put and ODC, while Spd and Spm remain unchanged resulting an apparently incomplete PSR. When stressors become chronic, they lead to a complete PSR and changes are also observed in Spd and Spm levels. However, persistent chronic stressors can activate a maladaptive PSR since they cause PA accumulation. Repeated stress events predispose to an increased risk of developing mental pathologies including depression, anxiety and in suicide, which often has comorbidity with mood and personality disorders (57).

\section{Polyamines and epilepsy}

Link between epilepsy and polyamines. Epilepsy is a neurological disorder characterized by the manifestation of spontaneous and repeated seizures, which are caused by disproportionate and simultaneous electrical activity of neuronal networks. This disorder is one of the most common worldwide neurological diseases; its incidence in the population is estimated to be $1-2 \%$ (59). In most cases, the disease is idiopathic, since the factors triggering epilepsy are unknown; however, some cases can be related to hereditary factors or to a brain injury. Epilepsy is classified into different categories: childhood absence epilepsy, benign focal epilepsy, juvenile myoclonic epilepsy and temporal lobe epilepsy (TLE). The latter is the most common epilepsy occurring in adults (60-62). Over the years, different research groups have focused their studies on the role that PAs could have in the molecular mechanisms underlying epilepsy. Since the knowledge, derived from clinical human studies, was not sufficient to improve understanding of the epileptic pathways, it was necessary to use the correct genetic models. In fact, extensive studies have been carried out using animal models in order to characterize the different form of epilepsy and better define the physiological importance of PAs in order to develop treatment therapies to be applied in epilepsy $(22,63-71)$.

Mouse models of epilepsy. The epilepsy animal models used provide seizure induction by chemoconvulsants, traumatic brain injury and electrical or sound stimuli. Among the most used chemoconvulsants are included Pentylenetetrazole (PTZ) and kainic acid (KA). Epileptic seizures induced by PTZ and KA have also been used in transgenic mouse models characterized by a deregulation of the PA system caused by the overexpression of PA metabolic enzymes. The transgenic mouse line K2 (63) overexpressing ODC in the brain and

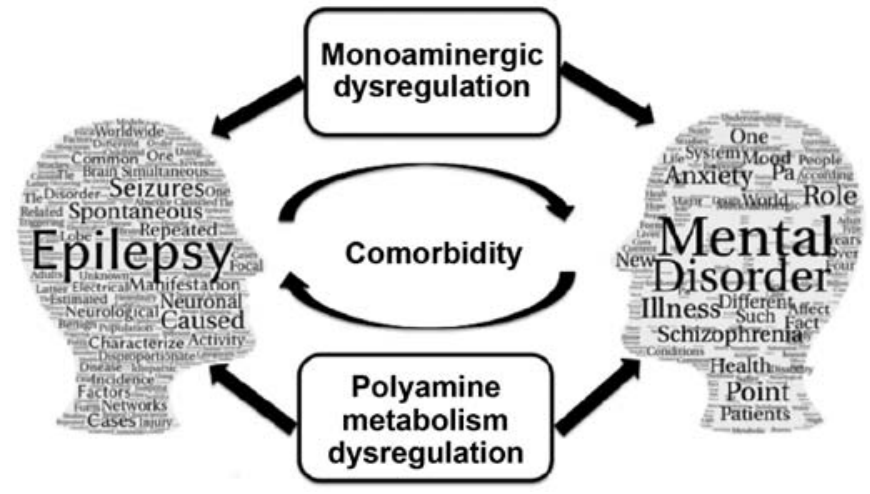

Figure 3. Potential association between monoaminergic system and polyamines in epilepsy and mental disorders.

consequently having a high Put cellular content, was shown to be neuro-protected from physically (electroshock) and chemically (PTZ) induced seizure activity (64), but displayed impaired spatial learning, vision, swimming ability and lack of motivation (64). The deficit in spatial learning was demonstrated to be associated with a constitutively high Put level as a result of its antagonistic effect on the NMDA receptor. Additionally, in transgenic rats overexpressing ODC (65) subjected to transient focal cerebral ischaemia, significantly smaller stroke lesions were observed in comparison with control rats, confirming that induction of ODC and the subsequent accumulation of Put are neuro-protective responses in the transient cerebral ischaemia (72). The transgenic mouse line ubiquitously overexpressing SSAT and generated by Pietilä et al (66), likewise the ODC over-expressing line mentioned above, displayed a high level of Put in the brain as a result of SSAT overexpression. These transgenic mice showed neuroprotection from KA-induced neuronal toxicity (67) and an elevated threshold to PTZ-induced convulsions in comparison with wild-type animals (68). Neurobehavioral profiling of SSAT overexpressing mice showed impaired spatial learning and the mice were revealed to be hypomotoric and less aggressive than wild-type animals (69). Although Put is a weak antagonist of the NMDA receptor (29), its elevated content in the brain could cause a partial blockade of this receptor, therefore giving protection to the transgenic animals from seizure activity, ischaemia reperfusion damage while producing impaired spatial learning $(68,69)$. A mouse Cre/loxP-based genetic model overexpressing SMOX specifically in neocortex neurons (Dach-SMOX, former JoSMOrec) has been engineered by Cervelli et al (70) to investigate the role of this enzyme and its substrate Spm, which is the strongest PA modulator of glutamatergic receptors, and certain types of $\mathrm{K}^{+}$channels and $\mathrm{Na}^{+}$channels $(27,73,74)$. Interestingly, Dach-SMOX mice showed a phenotype with significant astroglial and microglial activation in the neocortex of old animals, showing more pronounced brain damage during ageing. Furthermore, in excitotoxic conditions induced by KA injection, Dach-SMOX mice were more sensitive than control animals $(22,71)$. Compared with transgenic ODC and SSAT overexpressing mice, which displayed a neuroprotective response to different insults, Dach-SMOX animals showed the opposite phenotype, since increased neurodegeneration was 
observed during ageing and following KA injection (70,72). The production of $\mathrm{H}_{2} \mathrm{O}_{2}$ and 3-AP, derived from Spm oxidation, together with direct effects of Spm on AMPA and KA receptors, are synergistically involved in ROS increase and in the end, to neuronal degeneration and death. In conclusion, all these engineered transgenic rodent lines may represent useful in vivo genetic models for studying PA metabolism dysregulation in brain pathological conditions due to various physically and chemically induced excitotoxic insults that induce epilepsy $(70,75)$.

\section{Mood disorders and epilepsy}

The coexistence of two or more pathologies in the same person is defined as comorbidity. The link between these altered conditions can be associated with genetic and environmental factors as well as with common pathogenic mechanisms. The comorbidity between epilepsy and psychiatric diseases has not been considered for a long time. Over the last few years, several epidemiological studies have shown a strong correlation between epilepsy and different mental illnesses. Several studies demonstrated that among the many mental illnesses, those prevalent in epileptic patients are mood and anxiety disorders (76-82). In particular, anxiety appears to have a greater incidence (83). Of the people suffering from epilepsy, $\sim 6 \%$ of them present psychiatric comorbidity; this percentage increases in patients with TLE and/or refractory epilepsy reaching peaks of 60-80\% (82). It is very interesting that the amygdala, a region of the brain often involved in some types of epilepsy, is also implicated in the neurobiology of anxiety. The amygdala plays a key role in the manifestation of emotional and behavioural responses and by different hypothalamic pathways can activate neuroendocrine and autonomic responses (81). These responses take place during stressful circumstances. One of the most reliable hypotheses is that activation of these neuronal circuits together with an excessive excitability of the related neurons may be responsible of the manifestation of anxiety $(79,84)$. Notably, the amygdala plays a key role also in the most common form of epilepsy, TLE, which is also the most resistant to pharmacological treatments (85). Moreover, a proof of the relationship between anxiety and epilepsy is that the pharmacological treatment of anxiety is often carried out using specific anti-epileptic drugs such as benzodiazepines (86). It has been demonstrated that psychiatric factors could be predictive of response to treatments of seizure disorders. It has been demonstrated that epileptic patients with psychiatric comorbidity show a reduced response to pharmacological treatments. In fact, a study conducted by Hitiris et al (87) on 780 patients with new-onset epilepsy showed that if they had a previous diagnosis of psychiatric illness they were twice as likely to develop drug resistance to anti-epileptic treatments. Furthermore, the study by Kanner (88) proved that mental diseases could cause worse responses to surgical procedures for epilepsy.

\section{Conclusion}

For a long time, the link between epilepsy and mental disorders has been attributed exclusively to the serotonergic system. Several studies, in fact, have shown how an epilepsy animal model displayed alterations in serotonergic system both in terms of release of serotonin and of deficit in pre/post synaptic transmission of serotonergic neurons (89-91). The connection between noradrenaline and serotonin deficiencies and epilepsy have been found also in humans. The noradrenaline/serotonin theory proposed by Jobe and Browning (92) pointed out that mood disorder and epilepsy share a common background. In particular, the two pathologies display different neuronal circuits, defined intrinsic fabricators that start and maintain dysfunctional events. Nevertheless, they have the same exterior defensive shields in which noradrenaline and serotonin play a crucial role in the protection of the system against a malfunction of the intrinsic fabricators. Depending on which neuronal circuits are unbalanced, the development of epileptic or mental illnesses can be generated. As described previously, the monoaminergic system fails to explain all the events or all the pathways that lead to the development of mental illnesses, just as it is not possible to confirm that epilepsy is caused only by changes in monoamines. In this review, the authors wanted to focus on the role that PAs play in the CNS, proposing an evolution of the Jobe and Browning's theory in which, in addition to the noradreanalin/serotonin system, PAs could also be considered exterior defensive shields important to protect the brain from the development of epilepsy and mental illnesses (Fig. 3). In this context, the modulation of PA metabolism may be a new important target for the development of anti-epileptic, anxiolytic and anti-depressive drugs for the treatment of these diseases that affect health and quality of life and are important driver of health care costs.

\section{Acknowledgements}

The authors would like to thank the 'International Polyamine Foundation-ONLUS' for the availability to look up the polyamines documentation. The Grant to Department of Science, Roma Tre University (MIUR-Italy Dipartimenti di Eccellenza, ARTICOLO 1, COMMI 314 - 337 LEGGE 232/2016) is gratefully acknowledged.

\section{Funding}

No funding was received.

\section{Availability of data and materials}

Not applicable.

\section{Authors' contributions}

GB, JRS, EA, PM and MC conceived the present review, performed the literature search and wrote the manuscript. All authors have read and approved the final manuscript.

\section{Ethics approval and consent to participate}

Not applicable.

\section{Patient consent for publication}

Not applicable. 


\section{Competing interests}

The authors declare that they have no competing interests.

\section{References}

1. Thomas T and Thomas TJ: Polyamines in cell growth and cell death: Molecular mechanisms and therapeutic applications. Cell Mol Life Sci 58: 244-258, 2001.

2. Rea G, Bocedi A and Cervelli M: Question: What is the biological function of the polyamines? IUBMB Life 56: 167-169, 2004.

3. Wallace HM, Fraser AV and Hughes A: A perspective of polyamine metabolism. Biochem J 376: 1-14, 2003.

4. Li G, Regunathan S and Reis DJ: Agmatine is synthesized by a mitochondrial arginine decarboxylase in rat brain. Ann N Y Acad Sci 763: 325-329, 1995

5. Sastre M, Regunathan S, Galea E and Reis DJ: Agmatinase activity in rat brain: A metabolic pathway for the degradation of agmatine. J Neurochem 67: 1761-1765, 1996.

6. Moretti M, Matheus FC, de Oliveira PA, Neis VB, Ben J, Walz R, Rodrigues AL and Prediger RD: Role of agmatine in neurodegenerative diseases and epilepsy. Front Biosci (Elite Ed) 6: 341-359, 2014.

7. Cervelli M, Angelucci E, Stano P, Leboffe L, Federico R, Antonini G, Mariottini P and Polticelli F: The $\mathrm{Glu}^{216} / \mathrm{Ser}^{218}$ pocket is a major determinant of spermine oxidase substrate specificity. Biochem J 461: 453-459, 2014.

8. Cervelli M, Bellavia G, Fratini E, Amendola R, Polticelli F, Barba M, Federico R, Signore F, Gucciardo G, Grillo R, et al Spermine oxidase (SMO) activity in breast tumor tissues and biochemical analysis of the anticancer spermine analogues BENSpm and CPENSpm. BMC Cancer 10: 555, 2010.

9. Cervelli M, Angelucci E, Germani F, Amendola R and Mariottini P: Inflammation, carcinogenesis and neurodegeneration studies in transgenic animal models for polyamine research. Amino Acids 46: 521-530, 2014

10. Casero RA Jr, Murray Stewart T and Pegg AE: Polyamine metabolism and cancer: Treatments, challenges and opportunities. Nat Rev Cancer 18: 681-695, 2018.

11. Amendola R, Cervelli M, Fratini E, Polticelli F, Sallustio DE and Mariottini P: Spermine metabolism and anticancer therapy. Curr Cancer Drug Targets 9: 118-130, 2009.

12. Polticelli F, Salvi D, Mariottini P, Amendola R and Cervelli M: Molecular evolution of the polyamine oxidase gene family in Metazoa. BMC Evol Biol 12: 90, 2012.

13. Cervelli M, Salvi D, Polticelli F, Amendola R and Mariottini P Structure-function relationships in the evolutionary framework of spermine oxidase. J Mol Evol 76: 365-370, 2013.

14. Tavladoraki P, Cervelli M, Antonangeli F, Minervini G, Stano P, Federico R, Mariottini P and Polticelli F: Probing mammalian spermine oxidase enzyme-substrate complex through molecular modeling, site-directed mutagenesis and biochemical characterization. Amino Acids 40: 1115-1126, 2011.

15. Cervelli M, Polticelli F, Federico R and Mariottini $P$ : Heterologous expression and characterization of mouse spermine oxidase. J Biol Chem 278: 5271-5276, 2003

16. Cervelli M, Amendola R, Polticelli F and Mariottini P: Spermine oxidase: Ten years after. Amino Acids 42: 441-450, 2012

17. Poulin R, Casero RA and Soulet D: Recent advances in the molecular biology of metazoan polyamine transport. Amino Acids 42: 711-723, 2012.

18. Abdulhussein AA and Wallace HM: Polyamines and membrane transporters. Amino Acids 46: 655-660, 2014.

19. Seiler $N$ and Atanassov CL: The natural polyamines and the immune system. Prog Drug Res 43: 87-141, 1994.

20. Mastrantonio R, Cervelli M, Pietropaoli S, Mariottini P, Colasanti $M$ and Persichini T: HIV-Tat induces the Nrf2/ARE pathway through NMDA receptor-elicited spermine oxidase activation in human neuroblastoma cells. PLoS One 11: e0149802, 2016.

21. Igarashi K, Uemura $\mathrm{T}$ and Kashiwagi K: Acrolein: An effective biomarker for tissue damage produced from polyamines. Methods Mol Biol 1694: 459-468, 2018.

22. Pietropaoli S, Leonetti A, Cervetto C, Venturini A, Mastrantonio R, Baroli G, Persichini T, Colasanti M, Maura G, Marcoli M, et al: Glutamate excitotoxicity linked to spermine oxidase overexpression. Mol Neurobiol 55: 7259-7270, 2018
23. Leonetti A, Baroli G, Fratini E, Pietropaoli S, Marcoli M, Mariottini P and Cervelli M: Epileptic seizures and oxidative stress in a mouse model over-expressing spermine oxidase. Amino Acids: Jun 13, 2019 (Epub ahead of print).

24. Skatchkova SN, Antonovb SM and Eatona MJ: Glia and glial polyamines. Role in brain function in health and disease. Biochemistry (Moscow) Suppl Ser A Membr Cell Biol 10: 73-98, 2016.

25. Oliver D, Baukrowitz T and Fakler B: Polyamines as gating molecules of inward-rectifier $\mathrm{K}^{+}$channels. Eur J Biochem 267: 5824-5829, 2000

26. Li J, Doyle KM and Tatlisumak T: Polyamines in the brain Distribution, biological interactions, and their potential therapeutic role in brain ischaemia. Curr Med Chem 14: 1807-1813, 2007.

27. Williams K: Interactions of polyamines with ion channels. Biochem J 325: 289-297, 1997.

28. Pegg AE: Functions of polyamines in mammals. J Biol Chem 291 $14904-14912,2016$.

29. Williams K, Dawson VL, Romano C, Dichter MA and Molinoff PB: Characterization of polyamines having agonist, antagonist, and inverse agonist effects at the polyamine recognition site of the NMDA receptor. Neuron 5: 199-208, 1990.

30. Elsayed M and Magistretti PJ: A new outlook on mental illnesses: Glial involvement beyond the glue. Front Cell Neurosci 9: 468, 2015.

31. Sayers J: The world health report 2001-Mental health: New understanding, new hope. Bull World Health Organ 79: 1085, 2001.

32. Merikangas KR, Nakamura EF and Kessler RC: Epidemiology of mental disorders in children and adolescents. Dialogues Clin Neurosci 11: 7-20, 2009

33. Kamal R, Cox C and Rousseau D; Kaiser Family Foundation: Costs and outcomes of mental health and substance use disorders in the US. JAMA 318: 415, 2017.

34. Mkrtchian A, Aylward J, Dayan P, Roiser JP and Robinson OJ: Modeling avoidance in mood and anxiety disorders using reinforcement learning. Biol Psychiatry 82: 532-539, 2017.

35. Benarous X, Consoli A, Cohen D, Renaud J, Lahaye H and Guilé JM: Suicidal behaviors and irritability in children and adolescents: A systematic review of the nature and mechanisms of the association. Eur Child Adolesc Psychiatry 28: 667-683, 2019.

36. Ferrúa CP, Giorgi R, da Rosa LC, do Amaral CC, Ghisleni GC, Pinheiro RT and Nedel F: MicroRNAs expressed in depression and their associated pathways: A systematic review and a bioinformatics analysis. J Chem Neuroanat 100: 101650, 2019.

37. Furuyashiki T and Kitaoka S: Neural mechanisms underlying adaptive and maladaptive consequences of stress: Roles of dopaminergic and inflammatory responses. Psychiatry Clin Neurosci Jun 19: 2019 (Epub ahead of print).

38. Jin Y, Sun LH, Yang W, Cui RJ and Xu SB: The role of BDNF in the neuroimmune axis regulation of mood disorders. Front Neurol 10: 515, 2019.

39. Peirce JM and Alviña K: The role of inflammation and the gut microbiome in depression and anxiety. J Neurosci Res: May 29, 2019 (Epub ahead of print).

40. Schildkraut JS: The catecholamine hypothesis of affective disorders: A review of supporting evidence. Am J Psychiatry 122: 509-522, 1965

41. Whitaker-Azmitia PM: Serotonin and brain development: Role in human developmental diseases. Brain Res Bull 56: 479-485, 2001.

42. Liu Y, Zhao J, Fan X and Guo W: Dysfunction in serotonergic and noradrenergic systems and somatic symptoms in psychiatric disorders. Front Psychiatry 10: 286, 2019.

43. Fiori LM, Wanner B, Jomphe V, Croteau J, Vitaro F, Tremblay RE, Bureau A and Turecki G: Association of polyaminergic loci with anxiety, mood disorders, and attempted suicide. PLoS One 5: e15146, 2010

44. Andrews RC: The side effects of antimalarial drugs indicates a polyamine involvement in both schizophrenia and depression. Med Hypotheses 18: 11-18, 1985.

45. Fiori LM and Turecki G: Implication of the polyamine system in mental disorders. J Psychiatry Neurosci 33: 102-110, 2008.

46. Das I, de Belleroche J, Essali MA, Richardson-Andrews RC and Hirsch SR: Blood polyamine in schizophrenia. Schizophr Res 2: $146,1989$.

47. Meltzer HY, Arora RC, Jackman H, Pscheidt G and Smith MD: Platelet monoamine oxidase and plasma amine oxidase in psychiatric patients. Schizophr Bull 6: 213-219, 1980. 
48. Baron M, Asnis L, Gruen $\mathrm{R}$ and Levitt M: Plasma amine oxidase and genetic vulnerability to schizophrenia. Arch Gen Psychiatry 40: 275-279, 1983.

49. Dahel KA, Al-Saffar NM and Flayeh KA: Polyamine oxidase activity in sera of depressed and schizophrenic patients after ECT treatment. Neurochem Res 26: 415-418, 2001.

50. Bernstein HG, Grecksch G, Becker A, Höllt V and Bogerts B: Cellular changes in rat brain areas associated with neonatal hippocampal damage. Neuroreport 10: 2307-2311, 1999.

51. Middleton FA, Mirnics K, Pierri JN, Lewis DA and Levitt P: Gene expression profiling reveals alterations of specific metabolic pathways in schizophrenia. J Neurosci 22: 2718-2729, 2002

52. He Y, Yu Z, Giegling I, Xie L, Hartmann AM, Prehn C, Adamski J, Kahn R, Li Y, Illig T, et al: Schizophrenia shows a unique metabolomics signature in plasma. Trans Psychiatry 2: e149, 2012

53. Liu P, Jing Y, Collie ND, Dean B, Bilkey DK and Zhang H: Altered brain arginine metabolism in schizophrenia. Trans Psychiatry 6: e871, 2016.

54. Genedani S, Saltini S, Benelli A, Filaferro M and Bertolini A: Influence of SAMe on the modifications of brain polyamine levels in an animal model of depression. Neuroreport 12 3939-3942, 2001.

55. Reis DJ and Regunathan S: Is agmatine a novel neurotransmitter in brain? Trends Pharmacol Sci 21: 187-193, 2000

56. Askalany AR, Yamakura T, Petrenko AB, Kohno T, Sakimura K and Baba H: Effect of agmatine on heteromeric $\mathrm{N}$-methyl-D-aspartate receptor channels. Neurosci Res 52: 387-392, 2005

57. Gross JA and Turecki G: Suicide and the polyamine system. CNS Neurol Disord Drug Targets 12: 980-988, 2013.

58. Turecki G: Polyamines and suicide risk. Mol Psychiatry 18 $1242-1243,2013$

59. Naseer MI, Ullah I, Al-Qahtani MH, Karim S, Ullah N, Ansari SA, Kim MO and Bibi F: Decreased GABABR expression and increased neuronal cell death in developing rat brain after PTZ-induced seizure. Neurol Sci 34: 497-503, 2013.

60. Hauser WA and Kurland RT: The epidemiology of epilepsy in Rochester, Minnesota, 1935 through 1967. Epilepsia 16: 1-66, 1975.

61. Genton P and Bureau M: Epilepsy with myoclonic absences. CNS Drugs 20: 911-916, 2006.

62. Téllez-Zenteno JF and Hernández-Ronquillo L: A review of the epidemiology of temporal lobe epilepsy. Epilepsy Res Treat 2012: 630853, 2012.

63. Halmekytö M, Alhonen L, Wahlfors J, Sinervirta R, Eloranta T and Jänne J: Characterization of a transgenic mouse line over-expressing the human ornithine decarboxylase gene. Biochem J 278: 895-898, 1991.

64. Halonen T, Sivenius J, Miettinen R, Halmekytö M, Kauppinen R Sinervirta R, Alakuijala L, Alhonen L, MacDonald E and Jänne J: Elevated seizure threshold and impaired spatial learning in transgenic mice with putrescine overproduction in the brain Eur J Neurosci 5: 1233-1239, 1993.

65. Lukkarinen JA, Kauppinen RA, Gröhn OH, Oja JM, Sinervirta R, Järvinen A, Alhonen LI and Jänne J: Neuroprotective role of ornithine decarboxylase activation in transient focal cerebral ischaemia: A study using ornithine decarboxylase-overexpressing transgenic rats. Eur J Neurosci 10: 2046-2055, 1998.

66. Pietilä M, Alhonen L, Halmekytö M, Kanter P, Jänne J and Porter CW: Activation of polyamine catabolism profoundly alters tissue polyamine pools and affects hair growth and female fertility in transgenic mice overexpressing spermidine/spermine N1-acetyltransferase. J Biol Chem 272: 18746-18751, 1997.

67. Kaasinen K, Koistinaho J, Alhonen L and Jänne J: Overexpression of spermidine/spermine $\mathrm{N}$-acetyltransferase in transgenic mice protects the animals from kainate-induced toxicity. Eur J Neurosci 12: 540-548, 2000

68. Kaasinen SK, Gröhn OH, Keinänen TA, Alhonen L and Jänne J: Overexpression of spermidine/spermine N1-acetyltransferase elevates the threshold to pentylenetetrazol-induced seizure activity in transgenic mice. Exp Neurol 183: 645-652, 2003.

69. Kaasinen SK, Oksman M, Alhonen L, Tanila H and Jänne J: Spermidine/spermine N1-acetyltransferase overexpression in mice induces hypoactivity and spatial learning impairment. Pharmacol Biochem Behav 78: 35-45, 2004.
70. Cervelli M, Bellavia G, D'Amelio M, Cavallucci V, Moreno S, Berger J, Nardacci R, Marcoli M, Maura G, Piacentini M, et al: A new transgenic mouse model for studying the neurotoxicity of spermine oxidase dosage in the response to excitotoxic injury. PLoS One 8: e64810, 2013

71. Cervetto C, Vergani L,Passalacqua M, Ragazzoni M, Venturini A, Cecconi F, Berretta N, Mercuri N, D'Amelio M, Maura G, et al: Astrocyte-dependent vulnerability to excitotoxicity in spermine oxidase-overexpressing mouse. Neuromolecular Med 18: 50-68, 2016.

72. Alhonen L, Uimari A, Pietilä M, Hyvönen MT, Pirinen E and Keinänen TA: Transgenic animals modelling polyamine metabolism-related diseases. Essays Biochem 46: 125-144, 2009.

73. Fleidervish IA, Libman L, Katz E and Gutnick MJ: Endogenous polyamines regulate cortical neuronal excitability by blocking voltage-gated $\mathrm{Na}^{+}$channels. Proc Natl Acad Sci USA 105: 18994-18999, 2008.

74. Traynelis SF, Wollmuth LP, McBain CJ, Menniti FS, Vance KM, Ogden KK, Hansen KB, Yuan H, Myers SJ and Dingledine R: Glutamate receptor ion channels: Structure, regulation, and function. Pharmacol Rev 62: 405-496, 2010.

75. Jänne J, Alhonen L, Pietilä M and Keinänen TA: Genetic approaches to the cellular functions of polyamines in mammals. Eur J Biochem 271: 877-894, 2004

76. Chapouthier $G$ and Venault P. A pharmacological link between epilepsy and anxiety? Trends Pharmacol Sci 22: 491-493, 2001.

77. Harden CL and Goldstein MA: Mood disorders in patients with epilepsy: Epidemiology and management. CNS Drugs 16: 291-302, 2002

78. Kanner AM: Epilepsy and mood disorders. Epilepsia 48: 20-22, 2007.

79. Stahl SM: Brainstorms: Symptoms and circuits, part 2: Anxiety disorders. J Clin Psychiatry 64: 1408-1409, 2003.

80. Jackson MJ and Turkington D: Depression and anxiety in epilepsy. J Neurol Neurosurg Psychiatry 76 (Suppl 1): i45-i47, 2005.

81. Aroniadou-Anderjaska V, Qashu F and Braga MF: Mechanisms regulating GABAergic inhibitory transmission in the basolateral amygdala: Implications for epilepsy and anxiety disorders. Amino Acids 32: 305-315, 2007.

82. Hamid H, Ettinger AB and Mula M: Anxiety symptoms in epilepsy: Salient issues for future research. Epilepsy Behav 22: 63-68, 2011.

83. Gaitatzis A, Carroll K, Majeed A and W Sander J: The epidemiology of the comorbidity of epilepsy in the general population. Epilepsia 45: 1613-1622, 2004.

84. Rogawski MA and Löscher W: The neurobiology of antiepileptic drugs for the treatment of nonepileptic conditions. Nat Med 10: 685-692, 2004

85. Pitkänen A and Sutula TP: Is epilepsy a progressive disorder? Prospects for new therapeutic approaches in temporal-lobe epilepsy. Lancet Neurol 1: 173-181, 2002.

86. Mula M, Pini S and Cassano GB: The role of anticonvulsant drugs in anxiety disorders: A critical review of the evidence. J Clin Psychopharmacol 27: 263-272, 2007.

87. Hitiris N, Mohanraj R, Norrie J, Sills GJ and Brodie MJ: Predictors of pharmacoresistant epilepsy. Epilepsy Res 75: 192-196, 2007.

88. Kanner AM: Psychiatric issues in epilepsy: The complex relation of mood, anxiety disorders, and epilepsy. Epilepsy Behav 15: 83-87, 2009.

89. Theodore WH: Does serotonin play a role in epilepsy? Epilepsy Curr 3: 173-177, 2003.

90. Richerson GB: Serotonin: The anti-sudden death amine? Epilepsy Curr 13: 241-244, 2013.

91. Maia GH, Soares JI, Almeida SG, Leite JM, Baptista HX, Lukoyanova AN, Brazete CS and Lukoyanov NV: Altered serotonin innervation in the rat epileptic brain. Brain Res Bull 152: 95-106, 2019.

92. Jobe PC and Browning RA: The serotonergic and noradrenergic effects of antidepressant drugs are anticonvulsant, not proconvulsant. Epilepsy Behav 7: 602-619, 2005. 